\title{
Mathematical Model and Soft for the Heating Simulation of Metallic Parts in Solar Furnaces
}

\author{
Ioan CIOBANU \\ Transilvania University of Brasov, Romania, ciobanu_i_bv@yahoo.com \\ Maria STOICĂNESCU \\ Transilvania University of Brasov, Romania, stoican.m@unitbv.ro \\ Sorin Ion MUNTEANU \\ Transilvania University of Brasov, Romania, muntean.s@unitbv.ro \\ Vlad MONESCU \\ Transilvania University of Brasov, Romania, monescu@gmail.com
}

\begin{abstract}
Lately, more and more experimental research regarding the use of solar furnaces was conducted in order to thermally process different materials. In this direction, Transilvania University made a soft to simulate the heating of metallic parts in such furnaces. The soft is based on a 3D mathematical model, presented here with finite differences. The data concerning the structure of the soft and the results that can be delivered are also shown. This soft is useful to preset, by computer simulation, the working parameters of solar furnaces with concentrated flux regarding the concrete processing of some metallic pieces (volume thermal treatments, surface thermal treatment, melting, welding, covering with surface layers, etc.).
\end{abstract}

\section{Keywords}

mathematical modeling, heating simulation, solar furnace, heat treatment

\section{Introduction}

The development of science and technology, the increasing request of natural energy resources, together with the imperative of greening the manufacturing processes, in industry and economy, lead to the study and development of a new source of power and to the seek and set of a new manufacturing technology.

The sun represents an inexhaustible cheap and ecological solar energy. A first solar furnace with concentrated energy was built in France at Mont Louis, in Pyrenees, in 1949. Further on, more heavyduty installations were built, with concentrated solar energy (at Parkent City - Tashkent - Uzbekistan, Almeria - Spain, Neuchatel - Switzerland) [1,2]. The sun rays are trapped by a large sized mirror (heliostat) and directed towards a parabolic or spherical mirror (concentrator). Afterwards, this directs them in the shape of a concentrated spot towards its focal point where the objects to be heated are located. In such furnaces, temperatures of $4000^{\circ} \mathrm{C}$ [1-3] can be reached. Currently, research is conducted in the use of these solar furnaces (with concentrated energy) for the industrial processing of metallic alloys (thermal treatments, welding, alloy working, surface covering, etc.) [2-7].

\section{The Aims of the Paper}

Several softs were made at the Transilvania University, designed to simulate the thermal processing of metallic alloys. Thus, softs were made for the simulation of solidification of casted parts through different casting procedures and softs for cooling simulation of parts that were previously subjected to thermal treatments with heating in conventional furnaces [12-14]. The heating of metallic parts in solar furnaces constitutes a particular case of heating. If, in the case of classical heating installations (furnaces) the medium heating transfer, the part is predominantly made by convection or thermal conduction through the entire surface of the part, then in the case of heating in solar furnaces, this transfer is made through thermal radiation absorption, only on a small surface of the part. The specific power of the solar energy flux incident on the part's surface is very high and variable in time, 
but also relative to the energy spot axis. That is why the absorption coefficient of the radiant energy is greatly influenced by the condition of the part's surface (roughness, color, oxidation degree, temperature, etc.) that can be considerably changed during the heating process. As a result, the value of this coefficient is difficult to be established.

This is the reason why, in mathematical modelling of heating in solar furnaces in computer simulation of this type of processing, these particularities should be taken into account, so that the simplifier hypotheses do not affect greatly the precision of results.

This paper presents the mathematical model and the soft designed to simulate heating of metallic parts in solar furnaces at Transilvania University of Brasov. The mathematical model takes into consideration the phase (or structure) transformations that take place in materials heating and internal heat variation that accompanies this process [12-14]. It also regards the heating particularities in solar furnaces, mentioned above.

\section{The Principle of Mathematical Modeling}

The mathematical model realized is a 3D model and it uses the method of finite differences [8-14]. This can be applied to simulate the parts' heating with a complex geometry. The heating part-support ensemble is divided into cubic finite elements of $\Delta$ side, in a system of rectangular axis Oxyz. The position of the elements in the coordinate system is noted with the numerical coordinates " $i, j$ and $k$ ", that represent the serial / sequence number of the element on the three rectangular axes Ox, Oy and $\mathrm{Oz}$, where the counting starts at the origin of the axis system. The index $i$ has values between $1 \div n, j$ between $1 \div m$, and $k$ between $1 \div p$. What should be checked in the division process is the elements' composition in terms of material uniformity. Figures 1 and 2 shows the division principle of heated volume and the notation with parameters of the elements, oriented on the direction of the three axes $\mathrm{Ox}, \mathrm{Oy}$ and $\mathrm{Oz}$.

The total time of the simulation process is also divided into finite $\tau$ time intervals. The time of a certain moment during a $\tau_{q}$ process is stated as an integral multiple of the elementary time interval, through the relation $\tau_{q}=q \cdot \tau$, where $q$ represents the numerical coordinate of the time interval and it has integral values between $q=0$ and $q=q_{\max }$. The value $\tau_{0}=0$ (respectively $q=0$ ) corresponds to the initial moment of the process, and $\tau_{\max }=q_{\max } \cdot \tau$ (respectively $q=q_{\max }$ ) corresponds to the final moment of the simulated process.

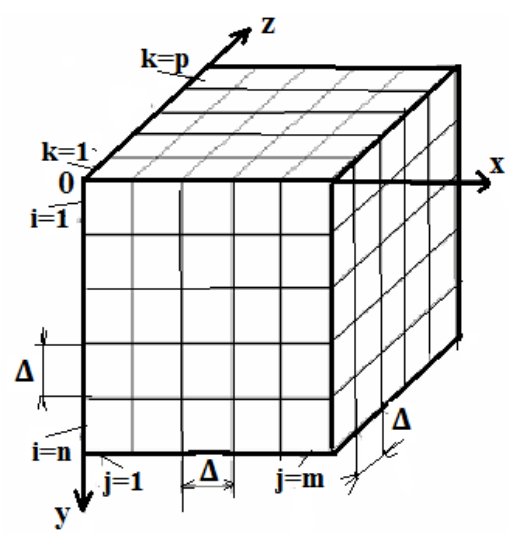

Fig. 1. Dividing the element subjected to heating in cubic volume elements of side $\Delta$ during modeling though finite differences

The designed mathematical 3D model takes into consideration the following hypotheses:

- the contact between discretized elements is perfect during the whole process;

- the heat transmission inside the heated system (part - support) takes place only through conductibility in the three perpendicular directions on the surface of the discretized elements;

- the evaporation, re-condensation and burning processes are neglected in the cast walls, together with the gas circulation through the cast's pores, considering an equivalent coefficient of heat transmission between elements; 


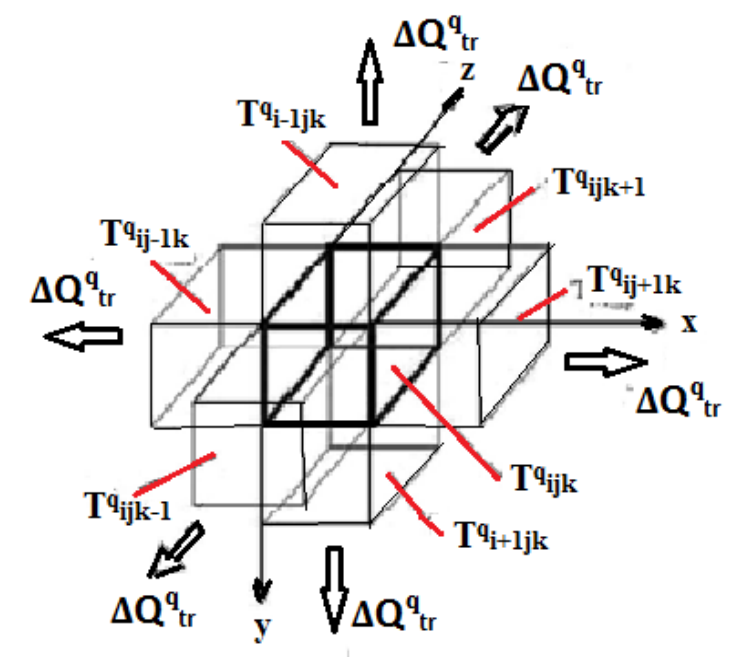

Fig. 2. Notation of the finite elements temperature in the case where the element is subjected to heating in 3D modeling

- the heat exchange between the part, support and environment is produced by convection;

- the elements situated on the incidence surface of the solar rays concentrated spot, situated inside the spot perimeter, receive heat through radiant energy absorption according to the value of the absorption coefficient;

- the structural transformations (phase transformations) are taken into consideration by considering the absorbed or given in heat (the variation of internal heat) during these transformations;

- the division network step remains constant during heating;

- the density is considered to be constant in terms of temperature because the volume variation is neglected in temperature, so that the division network step cannot be modified during simulation;

- the specific heat variation is considered, together with the thermal temperature conductibility with its structural transformations;

- the structural transformations are produced at a constant temperature, a valid hypothesis in the case of pure metals and alloys with eutectoid transformations or with a variation of the component solubility;

- at initial point, the temperature distribution is known in the elements of the system subjected to heating, the temperature in the cast walls and respectively in the liquid alloy uniformly distributed;

- the cast ensemble can be constituted from four types of materials, part, metallic support, ceramic support, etc.

\section{Notations}

The notations used for physical quantities that intervene in the elaborated mathematical model are generally similar to the ones used for other mathematical models and 3D softs in order to simulate thermal processes (for example, the solidification of casted parts from eutectic alloys). Each thermophysical quantity that characterizes the condition and the thermo-physical properties of the elements where the heated system is divided, is noted with four numeric parameters "i,j,k" - for the space numerical coordinates and "q" for the time numerical coordinate. The symbols of the physical quantities used during the mathematical 3D modeling of heating the parts in the solar furnace are the following:

- $\Delta$ - the space division network step (a side of the elements that are volume finite) where the system is divided in the $\mathrm{Ox}, \mathrm{Oy}, \mathrm{Oz}$ axis direction (figure 1);

- $\tau$ - the elementary time interval, the study of the process duration where the heat transfer is divided;

- $\mathrm{i}, \mathrm{j}, \mathrm{k}$ - numerical coordinates of volume elements, on the three $\mathrm{Ox}, \mathrm{Oy} ; \mathrm{Oz}$ axes (figure 1) where $i$ is the number of the element line in the matrix assigned to a section through cast, $j$ - the number of the column belonging to the volume element, $k$ - the number of the vertical layer parallel to the xOy plan; 
- $q$ - the time numerical coordinate (ordinal number of the elementary time interval $\tau$ );

- $n, m, p$ - the total number of lines , columns and layers, where the cast is divided (figure 1);

- $q_{\max }$ - the maximum value of the parameter $q$ (of time intervals for which the process in simulated);

- $\tau_{\max }$ - the total duration of the thermal transfer process;

- $T_{i j k}^{q}$ - the temperature of the element with numerical coordinates "i,j,k" at a $\tau_{q}$ moment (respectively for the numerical time coordinate $q$ );

- $T_{S i j k}$ - the structural transformation temperature (phasic) at a constant temperature of the element with the numerical coordinates " $\mathrm{i}, \mathrm{j}, \mathrm{k}$ ";

- $\xi_{i j k}^{q}$ - fraction that has a stabile structure at an ambient temperature of the element with numerical coordinates "i,j,k" at a moment $\tau_{q}$;

- $\left(1-\xi_{i j k}^{q}\right)$ is the fraction from the element mass that is structured according to the balance at a superior temperature to the transformation temperature, at a $q$ moment (thus the mass fraction that was subjected to the phase transformation at a $T_{S i j k}$ temperature);

- $\rho_{i j k}^{q}$ - density of the element with the "i,j,k" numerical coordinates at a $\tau_{q}$ moment;

- $L_{i j k}$ - specific latent structural transformation heat of the element with "i,j,k" numerical coordinates;

- $c_{S i j k}^{q}$ - specific heat in solid state for the element having the "i,j,k" coordinates at a $\tau_{q}$ moment;

- $c_{L i j k}^{q}$ - specific heat in liquid state for the element having the " $\mathrm{i}, \mathrm{j}, \mathrm{k}$ " coordinates at a $\tau_{q}$ moment;

- $\lambda_{S i j k}^{q}$ - the thermal conductibility coefficient in a solid state of the element having the "i,j,k" coordinates at a $\tau_{q}$ moment;

- $\lambda_{\text {Lijk }}^{q}$ - the thermal conductibility coefficient in liquid state of the element with " $\mathrm{i}, \mathrm{j}, \mathrm{k}$ " coordinates at a $\tau_{q}$ moment;

- $\lambda_{i j k}^{q}$ - thermal conductibility coefficient of the element having the " $\mathrm{i}, \mathrm{j}, \mathrm{k}$ " coordinates at a $\tau_{q}$ moment;

- $\alpha s_{i j k}^{q}$ - thermal transfer coefficient at a $\tau_{\mathrm{q}}$ moment, in the Ox axis, between the "i,j, $\mathrm{k}$ " element and the element situated in its left, (having the "i,j-1,k" coordinates) at a $\tau_{q}$ moment;

- $\alpha d_{i j k}^{q}$ - the thermal transfer coefficient at a $\tau_{q}$ moment in the Ox axis direction, between the "i,j, $\mathrm{k}^{\prime}$ element and the element situated at its right (with " $\mathrm{i}, \mathrm{j}+1, \mathrm{k}$ " coordinates) at $\tau_{q}$ moment;

- $\alpha h_{i j k}^{q}$ - the thermal transfer coefficient at a $\tau_{q}$ moment, in the Oy axis direction, between the "i,j,k" element and the element situated at its right (with "i-1,j,k") at a $\tau_{q}$ moment;

- $\alpha j_{i j k}^{q}$ - the thermal transfer coefficient at a $\tau_{\mathrm{q}}$ moment, in the direction of Oy axis, between the "i, j, k"

element and the element situated at its bottom (with " $\mathrm{i}+1, \mathrm{j}, \mathrm{k}$ " coordinates) at a $\tau_{\mathrm{q}}$ moment;

- $\alpha f_{i j k}^{q}$ - the thermal transfer coefficient at a $\tau_{q}$ moment in the direction of $\mathrm{Oz}$ axis, between the "i,j,k" element and the element situated in its front (with "i,j,k-1" coordinates) at a $\tau_{q}$ moment;

- $\alpha p_{i j k}^{q}$ - the thermal transfer coefficient at a $\tau_{q}$ moment in the direction of Oz axis, between the "i,j,k" element and the element situated in its back (with " $\mathrm{i}, \mathrm{j}, \mathrm{k}+1$ " coordinates) at a $\tau_{q}$ moment; - $\left(\Delta Q_{i j k}^{q}\right)_{t r}$ - the heat changed by the "i,j,k" element with close elements, in the elementary time interval $\tau$ at a $\tau_{q}$ moment;

- $\left(\Delta Q_{i j k}^{q}\right)_{m}$ - the variation of internal heat of the "i,j,k" element at a $\tau_{q}$ moment, as a result of the temperature variation or of the solidified fraction, in the elementary time interval $\tau$;

- $\left(Q_{s s}^{q}\right)_{i j k},\left(Q_{s d}^{q}\right)_{i j k},\left(Q_{s f}^{q}\right)_{i j k},\left(Q_{s p}^{q}\right)_{i j k},\left(Q_{s j}^{q}\right)_{i j k},\left(Q_{s h}^{q}\right)_{i j k}$ - the heat changed by the central element "i,j,k" with its left element, right, front, back, bottom and above (figure 3); 
- $\left(P_{\max }\right)_{i j \mathrm{k}}$ - the specific solar power maximum incident on the surface of the " $\mathrm{i}, \mathrm{j}, \mathrm{k}$ " element of the part;

- $C_{C L}^{q}$ - the decrement coefficient of the maximum solar flux by the adjustment of the solar installation louvers;

- $\left(Q_{i j k}^{q}\right)_{i n}$ - the specific solar energy flux, incident on the surface of a "i,j,k" element of the part at a " $q$ " moment;

- $\left(Q_{i j k}^{q}\right)_{a b s}$ - the specific solar energy flux, absorbed though the surface of a "i,j,k" element pf the part at a " $q$ " moment;

- $\left(C_{i j k}^{q}\right)_{a b s}$ - the absorption coefficient of the solar energy incident of the surface of the "i,j,k" element at a " $q$ " moment.

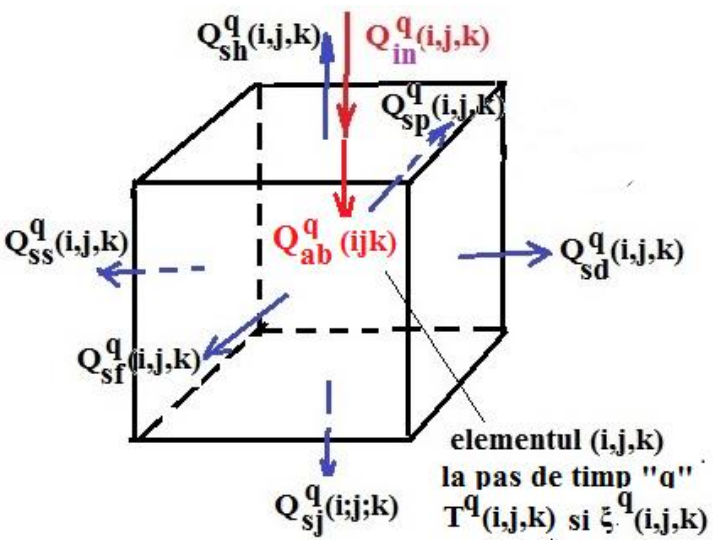

Fig. 3. Notation of heating changed by a finite element "i,j,k" with close elements to the " $q$ " moment;

$$
Q_{i n}^{q}(i, j, k) \text { - incident solar heat, } Q_{a b}^{q}(i, j, k) \text {-absorbed solar heat }
$$

\section{The Equations of the Mathematical Model}

At a random $\tau_{q}=q \cdot \tau$ moment (with a $q$ time coordinate after $q$ elementary time intervals) the condition of each volume element " $\mathrm{i}, \mathrm{j}, \mathrm{k}$ " (where the part-support ensemble subjected to heating is divided) is characterized by a momentary $T_{i j k}^{q}$ temperature and by the untransformed structure (mass) fraction $\xi_{i j k}^{q}$. At the initial moment, these quantities are noted with $T_{i j k}^{0}$ and respectively $\xi_{i j k}^{0}$. At the initial moment $(q=0)$ the initial structure fraction (untransformed) is $\xi_{i j k}^{0}=1$. Below the structural transformation temperature (phase transformation, as for the steel below the transformation temperature of the pearlite- austenite eutectoid) $\xi_{i j k}^{q}=1$. Above this temperature $\xi_{i j k}^{q}=0$, and for the elements that are transforming (that are at a $T_{S i j k}$ temperature at a certain moment, $\xi_{i j k}^{q}$ has values between 0 and 1 .

The mathematical model is based on the thermal balance equation of the discretized elements according to an elementary time interval $\tau$. The thermal balance equation considers the heat transmission schema in figures 2-4. The thermal balance equation for the central element in figure 2 expresses the equality between the internal heat variation of this element and the absorbed heat form the incident solar flux plus the heat changed by that element with the six close elements:

$$
\left(\Delta Q_{i j k}^{q}\right)_{m}=\left(\Delta Q_{i j k}^{q}\right)+\left(Q_{i j k}^{q}\right)_{a b s}
$$

The heat changed (received) by the element " $\mathrm{i}, \mathrm{j}, \mathrm{k}$ " with the close elements (or with the environment) by the six side surfaces $\Delta$, is calculated based on the design in Figures 2-4 by the relation is given by the relation: 


$$
\left(\Delta Q_{i j k}^{q}\right)_{t r}=\left[\begin{array}{l}
\alpha s_{i, j, k}^{q}\left(T_{i-1, j, k}^{q}-T_{i j k}^{q}\right)+\alpha d_{i, j, k}^{q}\left(T_{i+1, j, k}^{q}-T_{i, j, k}^{q}\right)+h_{i, j, k}^{q}\left(T_{i, j-1, k}^{q}-T_{i, j, k}^{q}\right)+ \\
\alpha j_{i, j, k}^{q}\left(T_{i, j+1, k}^{q}-T_{i, j, k}^{q}\right)+\alpha f_{i, j, k}^{q}\left(T_{i, j, k-1}^{q}-T_{i, j, k}^{q}\right)+\alpha p_{i, j, k}^{q}\left(T_{i, j, k+1}^{q}-T_{i, j, k}^{q}\right)
\end{array}\right] \cdot(\Delta)^{2} \cdot \tau
$$

Fig. 4. Notation of temperatures and changed heat (in a $\tau$ time interval) by an "i,j,k" element with close elements at " $q$ " moment (xOy plan)

The notations have their meaning explained above.

The solar heat absorbed by an element situated on the surface of the part, at the incidence of the solar flux, is calculated according to the specific incident power and the absorption coefficient by the relation:

In relation (3):

$$
\left(Q_{i j k}^{q}\right)_{a b s}=\left(C_{i j k}^{q}\right)_{a b s} \cdot C_{C L}^{q} \cdot\left(P_{\max }\right)_{i j k} \cdot \Delta^{2} \cdot \tau
$$

$\left(P_{\max }\right)_{i j k}$ is the specific power maximum incident on the surface of an element represents the specific power (on the surface unit) solar incident at a maximum opening of the attenuator louvers. This depends on the position of the element in relation to the axis of the concentrated solar flux. On the concentrated solar flux axis (in the focal point plan) the maximum specific power has the highest value, and the value decreases in distance in relation to the focal point centre;

$C_{C L}^{q}$ - the decrement coefficient of the energy flux is variable in time. It is modified according to the opening of the attenuator louvers. During a part heating, the opening of the louvers is modified as necessary, to ensure a uniform heating speed;

$\left(C_{i j k}^{q}\right)_{a b s}$ - the absorption coefficient of the radiant energy through the surface of the part is also modified according to the temperature of the part, as a result of the surface oxidation and its colour change. Its value also depends on the nature of the alloy and the manufacturing method of the part's surface.

The internal heat variation of an element with " $\mathrm{i}, \mathrm{j}, \mathrm{k}$ " coordinates in a " $\tau$ " time interval depends on the initial condition of the element (characterized by $T_{i j k}^{q}$ and $\xi_{i j k}^{q}$ at a " $q$ " moment) and on the final condition (characterized by $T_{i j k}^{q+1}$ and $\xi_{i j k}^{q+1}$ at a " $q+1$ " moment, respectively after a $\tau$ time interval). In the case of the 3D model and the heating of a phase transformation alloy at a $T_{S}$ temperature when the elements heat content variation is expressed, the same nine situations are met as in the case of the alloy solidification modeling which, at solidification, presents an eutectic transformation. These cases are shown in the Table 1.

Below you can see the explanations for the relations of the internal heat variation calculus for the nine cases presented in Table 1.

1a). Heating or cooling below transformation temperature $\boldsymbol{T}_{S}$ (Table 1 , case 1a). If $T_{i j k}^{q}<T_{S i j k}$ and $\xi_{i j k}^{q}=1$, and $T_{i j k}^{q+1}<T_{S i j k}$ and $\xi_{i j k}^{q+1}=1$, the internal heat variation of the "ijk" element in the time interval $\tau$ is given by the relation: 


$$
\left(\Delta Q_{i j k}^{q}\right)_{m}=\Delta^{3} \cdot \rho_{i j k} \cdot c_{S i j k}^{q} \cdot\left(T_{i j k}^{q+1}-T_{i j k}^{q}\right) \text {. }
$$

Table 1. The illustration cases of the internal heat variation of the $\left(\Delta Q_{i j k}^{q}\right)_{m}$ elements according to the position of the $T_{i j k}^{q}$ and $T_{i j k}^{q+1}$ temperatures according to the $T_{S i j k}$ transformation temperature

\begin{tabular}{|c|c|c|c|}
\hline No. & $\begin{array}{l}\text { The evolution of the } \\
\text { parameters }\end{array}$ & The process type & $\begin{array}{c}\text { The temperature variation in the } \tau \text { time } \\
\text { interval }\end{array}$ \\
\hline $1 \mathrm{a}$ & $\begin{array}{c}T_{i j k}^{q}<T_{i j k}^{q+1}<T_{S i j k} \\
\xi_{i j k}^{q}=\xi_{i j k}^{q+1}=1\end{array}$ & Heating below $T s_{i j k}$ & T [ $\left.{ }^{0} \mathrm{C}\right]$ \\
\hline $1 b$ & $\begin{array}{c}T_{i j k}^{q}<T_{i j k}^{q+1}=T_{S} \\
\xi_{i j k}^{q}=1 ; 0<\xi_{i j k}^{q+1}<1\end{array}$ & $\begin{array}{l}\text { Heating up to the } \\
\text { transformation } \\
\text { temperature }\end{array}$ & 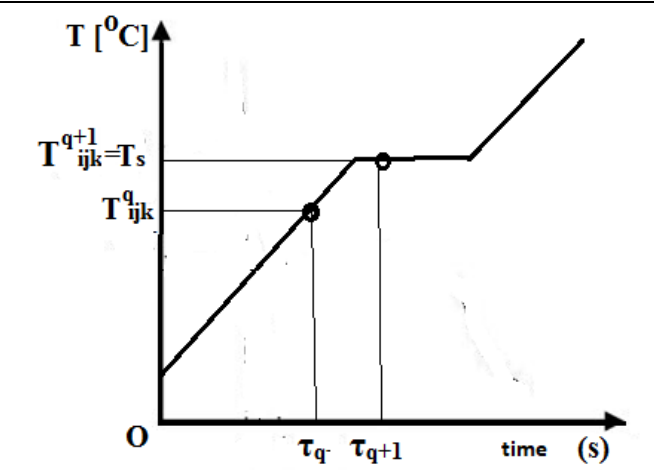 \\
\hline $1 \mathrm{c}$ & $\begin{array}{l}T_{i j k}^{q}<T_{S}<T_{i j k}^{q+1} \\
\xi_{i j k}^{q}=1 ; \xi_{i j k}^{q+1}=0\end{array}$ & $\begin{array}{l}\text { Heating above the } \\
\text { transformation } \\
\text { temperature }\end{array}$ & 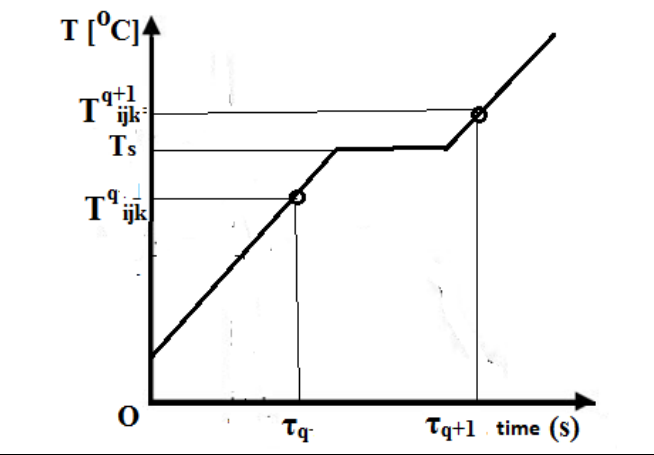 \\
\hline $2 a$ & $\begin{array}{c}T_{i j k}^{q}=T_{i j k}^{q+1}=T_{S} \\
\xi_{i j k}^{q} \in(0 ; 1) ; \xi_{i j k}^{q+1} \in(0 ; 1)\end{array}$ & $\begin{array}{l}\text { Transformation at } \\
\text { a } T_{S} \text { constant } \\
\text { temperature }\end{array}$ & 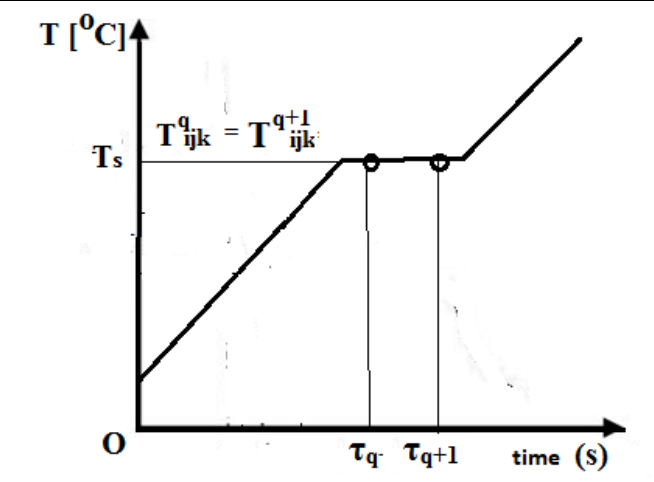 \\
\hline
\end{tabular}


RECENT, Vol. 19, no. 1(54), 2018

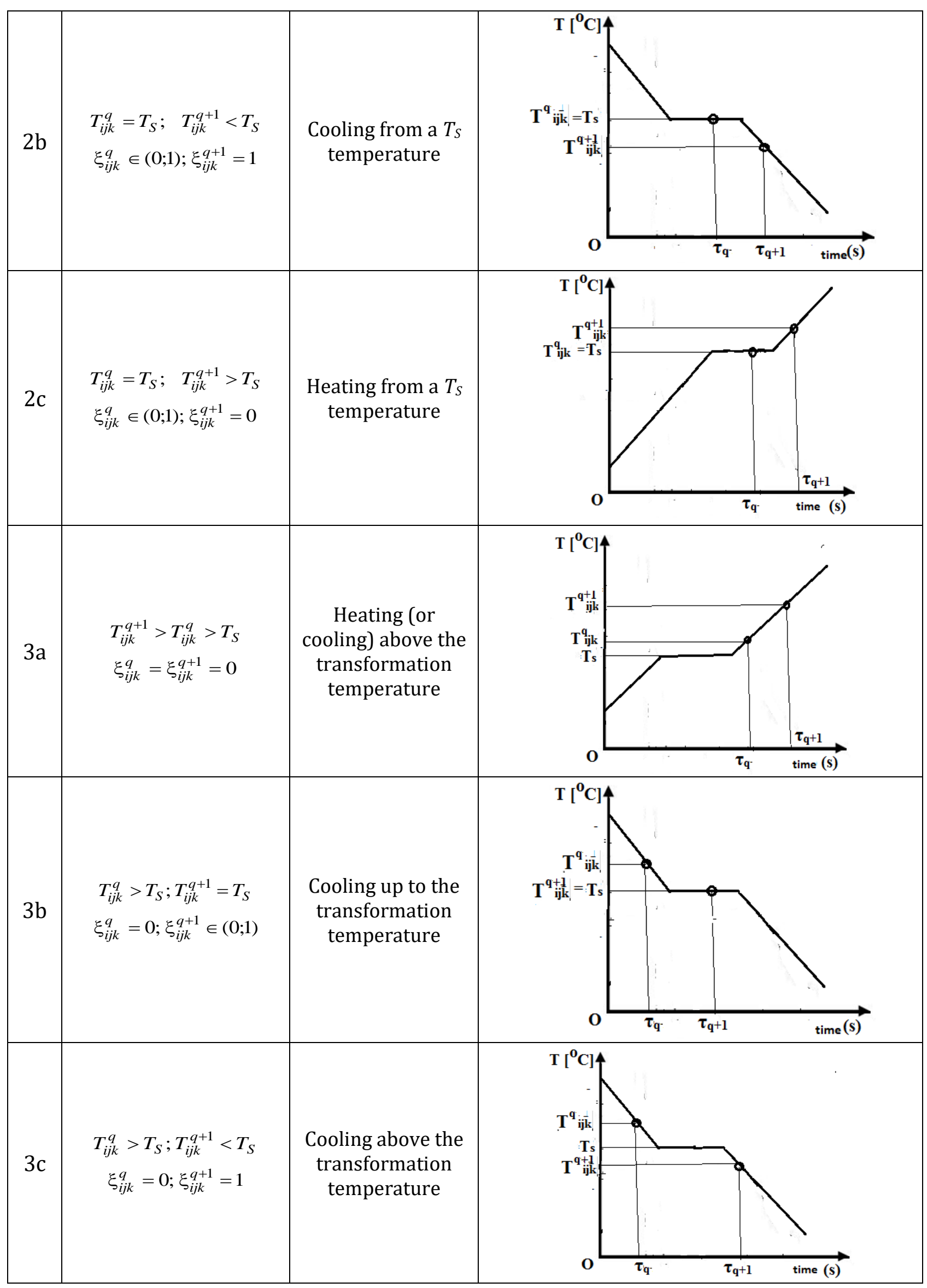


1b). Heating in solid state and partial transformation at $\boldsymbol{T}_{\boldsymbol{S}}$ (Table 1 , case $1 \mathrm{~b}$ ). If initially, at a $\tau_{q}$ moment, the element "ijk" has the structure completely balanced under $T_{S}$, its state is characterized by $T_{i j k}^{q}<T_{S i j k}$ and $\xi_{i j k}^{q}=1$, and at the moment $\tau_{q+1}$ the element state becomes $T_{i j k}^{q+1}=T_{S i j k}$ and the untransformed structure fraction (balanced under $T_{S}$ ) is $\xi_{i j k}^{q+1} \in[0 ; 1]$, then the variation of the internal heat is given by the relation:

$$
\left(\Delta Q_{i j k}^{q}\right)_{m}=\Delta^{3} \cdot \rho_{i j k} \cdot\left[c_{S i j k}^{q} \cdot\left(T_{S i j k}-T_{i j k}^{q}\right)-\left(1-\xi_{i j k}^{q+1}\right) \cdot L_{i j k}\right] .
$$

1c). Heating up to $T_{S}$, total structural transformation and heating above $T_{S}$ (Table1, case 1c). If at moment $\tau_{q}$ the state of the "ijk" element is characterized by $T_{i j k}^{q}<T_{S i j k}$ and $\xi_{i j k}^{q}=1$, and at a final moment $\tau_{q+1}$ the state of the element is $T_{i j k}^{q+1}>T_{S i j k}$ and the initial structure fraction (balanced at environmental temperature) is $\xi_{i j k}^{q}=0$, then the mass heat variation of the "ijk" element is given by the relation:

$$
\left(\Delta Q_{i j k}^{q}\right)_{m}=\Delta^{3} \cdot \rho_{i j k} \cdot\left\lfloor c_{S i j k}^{q} \cdot\left(T_{S i j k}-T_{i j k}^{q}\right)+L_{i j k}+c_{L i j k}^{q} \cdot\left(T_{i j k}^{q+1}-T_{S i j k}\right)\right] \cdot
$$

2a). Partial structure transformation at a constant transformation temperature $\boldsymbol{T}_{\boldsymbol{S}}$ (Table 1 , case $2 \mathrm{a}$ ). If at a $\tau_{q}$ moment, the temperature of the "ijq" element is $T_{i j k}^{q}=T_{S i j k}$ and $\xi_{i j k}^{q} \in[0 ; 1]$, and in the final state at a moment $\tau_{q+1}$ the state is $T_{i j k}^{q+1}=T_{S i j k}$ and $\xi_{i j k}^{q+1} \in[0 ; 1]$ the internal heat variation is:

$$
\left(\Delta Q_{i j k}^{q}\right)_{m}=\Delta^{3} \cdot \rho_{i j k} \cdot\left(\xi_{i j k}^{q}-\xi_{i j k}^{q+1}\right) \cdot L_{i j k} \cdot
$$

2b). Cooling from $T_{S}$, below the transformation temperature and full recoil to the balance structure of the environmental temperature (Table 1 . case $2 \mathrm{~b}$ ). If, at moment $\tau_{q}$, the temperature of the "ijk" element is $T_{i j k}^{q}=T_{S i j k}$ and $\xi_{i j k}^{q} \in[0 ; 1]$, and in the final state $T_{i j k}^{q+1}<T_{S i j k}$ and $\xi_{i j k}^{q+1}=1$ the internal heat variation is:

$$
\left(\Delta Q_{i j k}^{q}\right)_{m}=\Delta^{3} \cdot \rho_{i j k} \cdot\left[L_{i j k} \cdot\left(\xi_{i j k}^{q}-1\right)_{+} c_{S i j k}^{q} \cdot\left(T_{i j k}^{q+1}-T_{S i j k}\right)\right] .
$$

2c). Heating from $\boldsymbol{T}_{S}$ above this temperature and full structure transformation (Table 1, case 2c). If at $\tau_{q}$ moment, the temperature of the "ijk" element is $T_{i j k}^{q}=T_{S i j k}$ and $\xi_{i j k}^{q} \in[0 ; 1]$, and in final state $T_{i j k}^{q+1}>T_{S i j k}$ and $\xi_{i j k}^{q+1}=0$ then the mass heat variation is given by the relation:

$$
\left(\Delta Q_{i j k}^{q}\right)_{m}=\Delta^{3} \cdot \rho_{i j k} \cdot\left[\left(T_{i j k}^{q+1}-T_{i j k}^{q}\right) \cdot c_{L i j k}^{q}+L_{i j k} \cdot \xi_{i j k}^{q}\right] .
$$

3a). Heating (or cooling) above the transformation temperature $\boldsymbol{T}_{S}$ (Table 1, case $3 \mathrm{c}$ ). If the initial state is $T_{i j k}^{q}>T_{S i j k}$ and $\xi_{i j k}^{q}=0$, and after the time interval $\tau$ the parameters are $T_{i j k}^{q+1}>T_{S i j k}$ and $\xi_{i j k}^{q+1}=0$, the internal heat variation of the "ijk" element is given by the relation:

$$
\left(\Delta Q_{i j k}^{q}\right)_{m}=\Delta^{3} \cdot \rho_{i j k} \cdot\left(T_{i j k}^{q+1}-T_{i j k}^{q}\right) \cdot c_{L i j k}^{q} \cdot
$$

3b). Cooling up to $T_{s}$ and partial structure transformation in balance with a temperature below $\boldsymbol{T}_{\boldsymbol{S}}$ (Table 1, case $3 \mathrm{~b}$ ). If initially, at moment $\tau_{q}$ the state of the "ijk" element is characterized by $T_{i j k}^{q}>T_{S i j k}$ and $\xi_{i j k}^{q}=0$, and after the time interval $\tau$, at moment $\tau_{q+1}$ its state is characterized by $T_{i j k}^{q+1}=T_{S i j k}$ and $\xi_{i j k}^{q+1} \in[0 ; 1]$, then the mass heat variation is given by the relation:

$$
\left(\Delta Q_{i j k}^{q}\right)_{m}=\Delta^{3} \cdot \rho_{i j k} \cdot\left[\left(T_{S i j k}^{q}-T_{i j k}^{q}\right) \cdot c_{L i j k}^{q}-\left(1-\xi_{i j k}^{q+1}\right) \cdot L_{i j k}\right] .
$$


3c). Cooling from a superior temperature of $T_{S}$ to below $T_{S}$ and full structure transformation in balance below $\boldsymbol{T}_{S}$ (Table 1, case 3c). If initially $T_{i j k}^{q}>T_{S i j k}$ and $\xi_{i j k}^{q}=0$, and $T_{i j k}^{q+1}<T_{S i j k}$ and $\xi_{i j k}^{q+1}=1$, the internal heat variation of the "ijk" element is given by the relation:

$$
\left(\Delta Q_{i j k}^{q}\right)_{m}=\Delta^{3} \cdot \rho_{i j k} \cdot\left[\left(T_{S i j k}-T_{i j k}^{q}\right) \cdot c_{L i j k}^{q}-L_{i j k}+\left(T_{i j k}^{q+1}-T_{S i j k}\right) \cdot c_{S i j k}^{q}\right] \text {. }
$$

\section{The Solving Design of the Mathematical Model}

The logical solving design of the mathematical model to determine the temperature evolution in the subjected-to-heat part system, uses conditional relations, regarding the initial temperature of the discretized elements, $T_{i j k}^{q}$ and the final temperature $T_{i j k}^{q+1}$. In a first phase, it begins from the hypothesis that at the analyzed moment (at " $q$ " time coordinate) after the $\tau$ time interval (so, at moment $q+1$ ) the temperature of analyzed element with " $\mathrm{i}, \mathrm{j}, \mathrm{k}$ " coordinates, becomes equal to the solidification temperature (so $T_{i j k}^{q+1}=T_{S i j k}$ ). The structure fraction left untransformed $\xi_{i j k}^{q+1}$ is calculated at a $\tau_{q+1}$ moment. In case this calculated fraction does not converge in the $[0 ; 1]$ interval, the calculus is resumed and the correct final temperature $T_{i j k}^{q+1}$ is calculated. The logical design of the 3D model is systemized in three cases according to $T_{i j k}^{q}$, and then each case is subdivided into three sub-cases according to $T_{i j k}^{q+1}$.

Case 1: If the analyzed element "ijk" has $T_{i j k}^{q}<T_{S i j k}, \xi_{i j k}^{q}=1$, it is considered that $T_{i j k}^{q+1}=T_{S i j k}$ $0 \leq \xi_{i j k}^{q+1} \leq 1$. Then, in the thermic balance relation (1) the relations (2), (3) and (5) are replaced. The structure fraction left untransformed is then explained at a " $q+1$ " moment, $\xi_{i j k}^{q+1}$. The relation is obtained:

$$
\xi_{i j k}^{q+1}=\left[\frac{\left(\Delta Q_{i j k}^{q}\right)_{t r}+\left(Q_{i j k}^{q}\right)_{a b s}}{\Delta^{3} \cdot \rho_{i j k}}-\left(T_{S i j k}-T_{i j k}^{q}\right) \cdot c_{S i j k}^{q}+L_{i j k}\right] \cdot \frac{1}{L_{i j k}} .
$$

If the fraction left untransformed calculated herein converges in the $[0 ; 1]$ interval, then the temperature at a $\tau_{q+1}$ moment of the respective volume element is $T_{i j k}^{q+1}=T_{S i j k}$, and the mass untransformed fraction has the value resulted from the relation (13).

If the value of the solid fraction calculated with relation (13) is supra-uniform $\left(\xi_{i j k}^{q}>1\right)$ then, in the $\tau$ time interval, that element remains at a temperature below $T_{S}\left(T_{i j k}^{q+1}<T_{S i j k}\right)$ and the structure remains totally untransformed, and $\xi_{i j k}^{q+1}=1$. In this case, in the thermic balance equation (1) the relations (2), (3) and (4) are replaced, and the "ijk" element temperature at a $\tau_{q+1}$ moment is given by the relation:

$$
T_{i j k}^{q+1}=T_{i j k}^{q}+\frac{\left(\Delta Q_{i j k}^{q}\right)_{t r}+\left(Q_{i j k}^{q}\right)_{a b s}}{\Delta^{3} \cdot \rho_{i j k} \cdot c_{S i j k}^{q}} .
$$

If the value of the solid fraction calculated with the help of the relation (13) is negative $\left(\xi_{i j k}^{q+1}<0\right)$ then it means that in the time interval $\tau$ that element is completely transformed, the initial structure fraction becomes $\xi_{i j k}^{q+1}=0$, and the temperature at the end of the time interval is $T_{i j k}^{q+1}>T_{S i j k}$. In this case, in the thermic balance equation (1) the relations (2), (3) and (6) are replaced and the temperature of the "ijk" element at a $\tau_{q+1}$ moment is given by the relation:

$$
T_{i j k}^{q+1}=T_{S i j k}+\frac{\left(\Delta Q_{i j k}^{q}\right)_{t r}+\left(Q_{i j k}^{q}\right)_{a b s}-\Delta^{3} \cdot \rho_{i j k} \cdot\left[\left(T_{S i j k}-T_{i j k}^{q}\right) \cdot c_{S i j k}^{q}-L_{i j k}\right]}{\Delta^{3} \cdot \rho_{i j k} \cdot c_{L i j k}^{q}} .
$$


Case 2: If $T_{i j k}^{q}=T_{S i j k}$ and $0 \leq \xi_{i j k}^{q} \leq 1$. It is considered that $T_{i j k}^{q+1}=T_{S i j k}$ and $0 \leq \xi_{i j k}^{q+1} \leq 1$. Then in the thermic balance equation (1), the relations (2), (3) and (7) are replaced. By explaining the structure untransformed fraction $\xi_{i j k}^{q+1}$ the relation is obtained:

$$
\xi_{i j k}^{q+1}=\xi_{i j k}^{q}-\frac{\left(\Delta Q_{i j k}^{q}\right)_{t r}+\left(Q_{i j k}^{q}\right)_{a b s}}{\Delta^{3} \cdot \rho_{i j k} \cdot L_{i j k}} .
$$

If the fraction $\xi_{i j k}^{q+1}$ calculated above converges in the interval $[0 ; 1]$ the temperature at moment $\tau_{q+1}$ is $T_{i j k}^{q+1}=T_{S i j k}$, and the fraction in the untransformed structure at this moment has the value given by the relation (16).

If the value of the fraction calculated with the relation (16) is negative $\left(\xi_{i j k}^{q+1}<0\right)$ then it means that in the time interval $\tau$ the respective element transforms completely as structure in stabile structure at a superior $T_{S}$ temperature, and the initial structure fraction becomes $\xi_{i j k}^{q+1}=0$. The temperature at the end of the time interval will be $T_{i j k}^{q+1}>T_{S i j k}$. In this case, in the thermic balance equation (1), the relations (2), (3) and (9) are replaced, and the temperature of the "ijk" element at a $\tau_{q+1}$ moment is given by the relation:

$$
T_{i j k}^{q+1}=T_{S i j k}+\frac{\left(\Delta Q_{i j k}^{q}\right)_{t r}+\left(Q_{i j k}^{q}\right)_{a b s}-\Delta^{3} \cdot \rho_{i j k} \cdot L_{i j k} \cdot \xi_{i j k}^{q}}{\Delta^{3} \cdot \rho_{i j k} \cdot c_{L i j k}^{q}} .
$$

If the value of the solid fraction calculated with the relation (16) is supra-uniform $\left(\xi_{i j k}^{q+1}>1\right)$, then in the time interval $\tau$ that element recoils completely to the stabile structure at low temperatures (below $T_{S}$ ). The temperature at the end of the time interval will be $T_{i j k}^{q+1}<T_{S i j k}$, and the stabile structure fraction at low temperature is $\xi_{i j k}^{q+1}=1$. In this case, in the thermic balance equation the relations (2), (3) and (6) are replaced, and the temperature of "ijk" element at a $\tau_{q+1}$ moment is given by the relation:

$$
T_{i j k}^{q+1}=T_{S i j k}+\frac{\left(\Delta Q_{i j k}^{q}\right)_{t r}+\left(Q_{i j k}^{q}\right)_{a b s}+\Delta^{3} \cdot \rho_{i j k} \cdot L_{i j k} \cdot\left(1-\xi_{i j k}^{q}\right)}{\Delta^{3} \cdot \rho_{i j k} \cdot c_{S i j k}^{q}} .
$$

Case 3: If $T_{i j k}^{q}>T_{S i j k}, \xi_{i j k}^{q}=0$, and $T_{i j k}^{q+1}=T_{S i j k}, 0 \leq \xi_{i j k}^{q+1} \leq 1$, then in the thermic balance equation (1), the relations (2), (3) and (11) are replaced. By explaining the solidified fraction $\xi_{i j k}^{q+1}$ we get the relation:

$$
\xi_{i j k}^{q+1}=\frac{\Delta^{3} \cdot \rho_{i j k} \cdot c_{L i j k}^{q} \cdot\left(T_{i j k}^{q}-T_{S i j k}\right)+\left(\Delta Q_{i j k}^{q}\right)_{t r}+\left(Q_{i j k}^{q}\right)_{a b s}}{\Delta^{3} \cdot \rho_{i j k} \cdot L_{i j k}}-1 .
$$

If the structure fraction corresponding to low temperatures $\xi_{i j k}^{q+1}$ calculated herein converges in the $[0 ; 1]$ interval, the temperature $T_{i j k}^{q+1}=T_{S i j k}$, and at moment $\tau_{q+1}$ the stabile structure fraction at low temperature has the value given by the relation (19).

If the value of the calculated fraction with the relation (19) is negative $\left(\xi_{i j k}^{q+1}<0\right)$, it means that in the time interval $\tau$ that element remains with the structure corresponding to superior temperature of $T_{S}$. The structure fraction corresponding to low temperatures will be $\xi_{i j k}^{q+1}=0$, and the temperature at the end of the time interval $\tau$, will be $T_{i j k}^{q+1}>T_{S i j k}$. In this case, in the thermic balance equation (1), 
the relations (2), (3) and (10) are replaced, and the temperature of the "ijk" element at moment $\tau_{q+1}$ is given by the relation:

$$
T_{i j k}^{q+1}=T_{i j k}^{q}+\frac{\left(\Delta Q_{i j k}^{q}\right)_{t r}+\left(Q_{i j k}^{q}\right)_{a b s}}{\Delta^{3} \cdot \rho_{i j k} \cdot c_{L i j k}^{q}} .
$$

If the value of the solid fraction calculated with the relation (19) is supra-uniform $\left(\xi_{i j k}^{q+1}>1\right)$ then it means that in the time interval $\tau$ that element completely recoils to the stabile structure at low temperature. The final structure fraction is $\xi_{i j k}^{q+1}=1$, and the temperature at the end of the time interval will be $T_{i j k}^{q+1}<T_{S i j k}$. In this case, in the thermic balance equation, the relations (2), (3) and (11) are replaced and the temperature of the "ijk" element at moment $\tau_{q+1}$ is given by the relation:

$$
T_{i j k}^{q+1}=T_{S i j k}+\frac{\left(\Delta Q_{i j k}^{q}\right)_{t r}+\left(Q_{i j k}^{q}\right)_{a b s}-\Delta^{3} \cdot \rho_{i j k} \cdot c_{L i j k}^{q} \cdot\left(T_{S i j k}-T_{i j k}^{q}\right)+\Delta^{3} \cdot \rho_{i j k} \cdot L_{i j k}}{\Delta^{3} \cdot \rho_{i j k} \cdot c_{S i j k}^{q}} .
$$

To determine the evolution of the temperature in the part-support system subjected to heating, the solving design presented above for the calculus of temperature $T_{i j k}^{q}$ is progressively covered for all discretized elements, by running the computer program for all values of $i, j, k$ and respectively for all values of $q$.

\section{The Convergence of the Mathematical Model Solution}

As long as $\Delta-$ the step of the division system is smaller, the more precise are the results of the simulations. The equations system of the mathematical model represented by the thermic balance equations of the volume elements, is solvable (has a stabile solution) only if the value of the time step $\tau$, where is the duration of the heating process is divided, has a smaller value than a critical value $\left(\tau_{\mathrm{CRT}}\right)$. The critical value of the time step is conditioned by the step of the division system of the shape ensemble $(\Delta)$. That is why the value of the elementary time interval $\tau$ must be correlated to the value of the spatial system step " $\Delta$ ". In case the value of $\tau$ is higher than a critical value $\tau_{\mathrm{CRT}}$, the equations system of the mathematical model cannot be solved, because the solution oscillates. In this case, the equations system does not lead to a real solution for temperature $T_{i j k}^{q+1}$.

The convergence condition of the solution to solve the mathematical model is obtained considering that the heat transmission between the system elements is only produced from elements with higher temperature towards the elements with lower temperature and they stop only when the temperature of the six elements for which the explanation of the thermic balance equation (see fig. 2) is equalized. If the value adopted for $\tau$ is too high compared to $\Delta$, the value of the heat transmitted through conductibility by one element (central element in fig. 2) calculated with relation (2), is too high. This would lead, at a certain point, to a heat transmission from a colder element to a warmer one, which, naturally, is not possible.

The critical value, a limit of the time division $\tau_{\text {СRT }}$ that ensures the convergence of the mathematical model is determined from the condition that the temperature of the central element in the schema in fig. 2 does not drop below close elements' temperature. For interior cores of a tridimensional system, the convergence relation of the mathematical solution is:

$$
\tau_{C R T}=\frac{\Delta^{2}}{6 \cdot a}=\frac{\Delta^{2} \cdot c \cdot \rho}{6 \cdot \lambda} .
$$

In this relation $a$ represents the thermic diffusion coefficient, $c$ - the specific heat of the element, $\rho-$ density, and $\lambda$ - the thermic conductibility coefficient.

The value of the critical time $\left(\tau_{\mathrm{CRT}}\right)$ must be calculated for all possible situations, respectively for all materials (part, metallic support, ceramic support, etc.) and the structure variants from the system subjected to heating (by using the thermophysical properties corresponding to each material and structure, $\alpha, \lambda, \rho)$. 
It is necessary that, at the initializing of a simulation (setting some soft data regarding a simulation), the step $\tau$ to be chosen smaller than the smallest of the critical time values calculated for each material according to the relation:

$$
\tau<\min \left(\tau_{\mathrm{CRT}}\right)_{i},
$$

where $i=1-t$, where $t$ is the total number of materials and structures characterized by different thermophysical characteristics $(c, \rho, \lambda)$ from the system subjected to heating.

\section{Elements Regarding the Soft Structure}

Based on the mathematical model and its solving design, a soft for a 3D simulation has been designed for this process (SIM-3D-SOLAR-1 soft). Its structure considers the mathematical model solving design. The soft was designed with the hypothesis that the heating system of the part ensemble is built of maximum four types of materials: the part subjected to heating, metallic support, heat insulating or cooling support).

The MATLAB programming system was used. Some advantages offered by this system were considered in the case of physical processes simulation rendered by mathematical equations, that is:

- Simplicity and rapidity in realizing mathematical calculus, that uses symbols and mathematical functions;

- The possibility to work with spatial array of any dimensions;

- Facilities in mathematical processing of results;

- Facilities in the graphical representations of results;

- The possibility to graphically represent the results under different forms (cubic, histogram, colour map, level curve map, etc.);

- The possibility to simulate part heating with any geometry and dimensions.

The soft made works with four types of files, having the extensions „_.m”, „_.in” and „_.out” and „_.jpg". The files with the extension „_m” are working files that makes the calculus based on the functional relations between the heating process parameters and the mathematical model equations. The files „_.in” are files where the user introduces (sets) data referring to selecting and graphically representing the results. The files „_.out” have the results required by user and they are shown in a table. The files „_.jpg" present the results graphically.

Based on the mathematical model, the computer program uses as initial data the parameters and the thermo-physics parameters of each material in the system. When work is launched, the program calculates the parameters $\xi_{i j k}^{q+1}$ and $T_{i j k}^{q+1}$ at moment $\tau_{q+1}$. The cycle is resumed for the next time step, until the maximum number of steps performed $\left(q_{\max }\right)$ set by the program user. The value " $q_{\max }$ " is established according to the duration for which the heating process is studied $\left(\tau_{\max }\right)$.

\section{Obtained Results}

Results referring to the metallic parts heating in solar furnaces, obtained with the use of this soft (SIM-3D-SOLAR-1) are shown in tables in files with the extension "_.out". The soft supplies the following results:

- The tridimensional (3D) space matrix of temperature repartition in the volume ensemble partsupport at the end of the simulation (at moment $\tau_{\max }=q_{\max } \cdot \tau$ ) and at any " $q$ " moment required by user at simulation initialization;

- The matrix of temperature repartition in part-support ensemble in any transversal section (parallel to $\mathrm{xOy}$ or $\mathrm{yOz}$ plans) at any moment required by user at simulation initialization; these results are given in a table (as a bi-dimensional matrix) or as a colour and curve map in $\mathrm{xOy}$ or $\mathrm{yOz}$ coordinates;

- Heating time matrix to the structural transformation temperature $\left(T_{S}\right)$ of all the discretized volume elements;

- The evolution in time of the temperature, stabile structure fraction at low temperatures (below $T_{S}$ ) and the local heating speed at any point (discretized volume element) from the system subjected to heating. The values of the temperature $\left(T_{i j k}\right)$, of the untransformed fraction $\left(\xi_{i j k}\right)$ and of the local heating speed are shown in a table or in a graph (as dependent of time functions); 
- The temperature repartition on different lines or column form the part-support ensemble at different " $q$ " moments (set by user at simulation initialization); these results are shown in a table and graph as curves in temperature coordinates - spatial coordinates (distance to the origin of the system on axes $\mathrm{Ox}$ or $\mathrm{Oy}$ or $\mathrm{Oz}$ );

- The matrix of temperature repartition in all points of the ensemble at different set moments.

The " $q$ " time coordinates - for which these values are memorized are introduced at program initialization in the file "timpi impuși.in" (set time.in); the files with this data are marked as TKN_q, where $q$ is the time coordinate for which data is memorized;

Based on the table results, the program renders the following graphic representations:

- The repartition of the isotherm in the part-support system at the end of the structure transformation moment;

- The temperature variation curves, of the stabile structure below $T_{S}$ and the heating speed (temperature variation) according to time, in all volume elements "ijk" set by user at a simulation initialization;

- Temperature repartition curves on lines and columns of the division system at moments set by user at initialization;

- The position (misalignment) of the transformation front of the structure at different moments in any vertical section (xOy or $\mathrm{xOz}$ );

- The position of the transformation front of the structure at any " $q$ " moment set by user at program initialization;

- The curve map that shows the transformation front misalignment of the structure according to time, in any section of the part;

- Curves that show the position of the transformation front at a certain moment set by user at initialization.

Also, by processing the data memorized by the soft it is possible that information regarding the temperature gradient in any point (any discretized volume element) at any moment of heating to be obtained.

To exemplify the results, a heating simulation was performed in a vertical solar furnace with a concentrated flux of a steel sample having the dimensions $33 \times 25 \times 10 \mathrm{~mm}$. The shape and dimensions of the heated part are given in Figures 5 and 6. The following values were considered for the working parameters of the solar furnace:

- Progressive opening of the attenuator louvers between 3-23\% (according to some experiments carried on the mentioned installation);

- The steel part is placed on a copper plate, and then on a ceramic heat-proof plate;

- The incident specific power of the spot on the superior surface of the sample was considered as: in the central zone (in a range of $10 \mathrm{~mm}$ ) a medium power of Qin1 $=6,300,000 \mathrm{~W} / \mathrm{m}^{2}$ and in the rest of the surface a medium power Qin2 $=5,500,000 \mathrm{~W} / \mathrm{m}^{2}$ (these values regarded the real incident power in the focal plan of the concentrator in some experiments);

- For the absorption coefficient of radiation on the surface of the sample, a medium value $\mathrm{Ca}=0.8-0.75$ was considered at temperatures below $800{ }^{\circ} \mathrm{C}$ and $\mathrm{Ca}=0.65-0.6$ at temperature in the interval $850-950^{\circ} \mathrm{C}$ where the sample surface becomes incandescent;

- A medium heat exchange coefficient equivalent (convection + radiation) sample - environment on lateral and bottom surfaces $\alpha \mathrm{ex}=24 \mathrm{~W} / \mathrm{m}^{2} \mathrm{C}$;

- Heating time $t=23.3$ minutes;

- Heating time $t=23.3$ minutes.

These values were set considering heating experiments of some steel samples on solar furnaces in Almeria - Spain. The part (steel) - support (copper + ceramic heat insulating plate) ensemble subjected to heating was divided in cubic volume elements with a side $\Delta=1 \mathrm{~mm}$, as shown in Figure 5 . The time step to determine the evolution of the temperature in the sample points was $t=0.0025$ seconds. The discretization design that stands as a base for the mathematical model is shown in Figure 6.

The temperature determined by simulation represents the medium temperature, for the moment of the cubic volume elements (as a results of the system division) with the side $\Delta=1 \mathrm{~mm}$. 
In Table 2 the volume elements temperature are given with the side $\Delta=1 \mathrm{~mm}$ from the section $\mathrm{OABC}$ of the sample (Figure 6) at time $\mathrm{t}=23.3 \mathrm{~min}$.

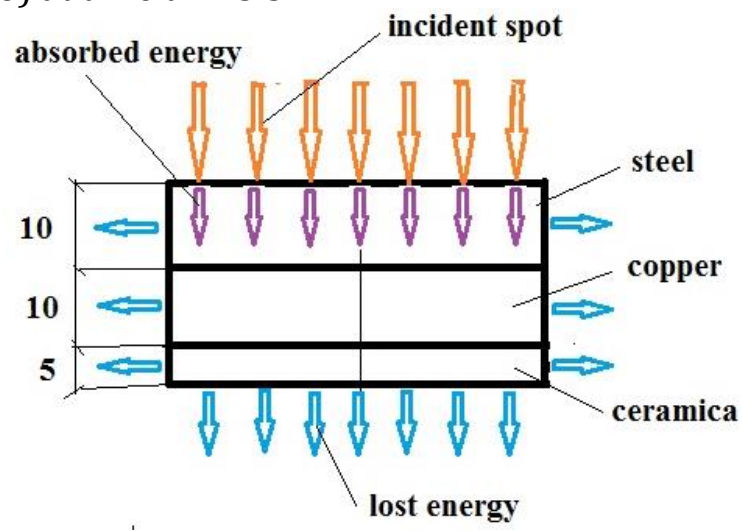

Fig. 5. The design of mathematic model for simulation

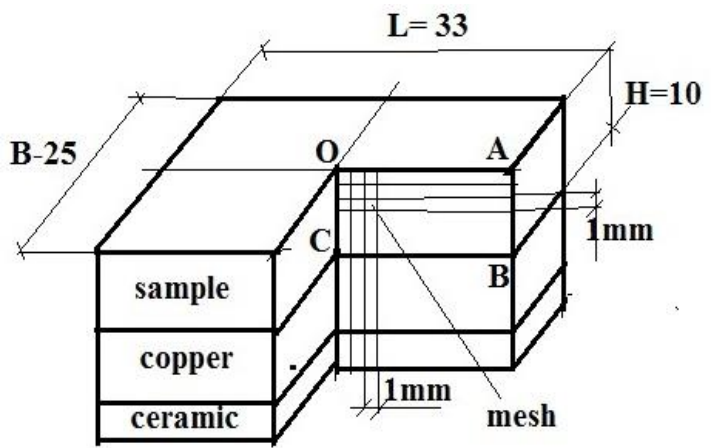

Fig. 6. Meshing of the sample - support system for heating simulation

Table 2. Simulated results - temperature (in ${ }^{\circ} \mathrm{C}$ ) in the volume elements of the part in $\mathrm{OABC}$ section (Figure 6) at time $t=23.3 \mathrm{~min}$

\section{Number of column $=$ distance in $\mathrm{mm}$}

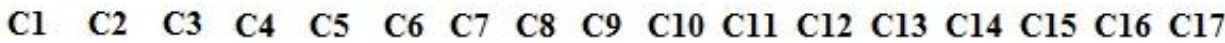

Temperature, in grd. $\mathrm{C}$

O Pyrometer point

Thermocouple point A

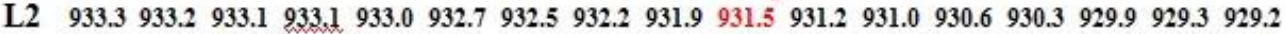

L3 931.0 931.0 931.0 930.8930 .7930 .5930 .3930 .1929 .8929 .5929 .2928 .9928 .6928 .3928 .0927 .7927 .3

L4 928.9928 .8928 .8928 .7928 .6928 .4928 .3928 .1927 .8927 .6927 .3927 .0926 .7926 .4926 .1925 .8925 .4

L5 926.8926 .8926 .9926 .7926 .6926 .4926 .3926 .1925 .9925 .7925 .4925 .2924 .9924 .6924 .4924 .0923 .7

L6 924.9924 .9924 .8924 .7924 .6924 .5924 .4924 .2924 .1923 .9923 .7923 .4923 .2923 .0922 .6922 .3922 .0

L7 923.0923 .0922 .9922 .9922 .8922 .7922 .6922 .4922 .3922 .1921 .9921 .7921 .5921 .3921 .0920 .7920 .4

L8 921.2921 .2921 .1921 .1921 .0920 .9920 .8920 .7920 .6920 .4920 .3920 .1919 .9919 .7919 .5919 .2918 .9

L9 919.5919 .4 919.4 919.4. 919.3919.2 919.2 919.1 919.0 918.8918.7 918.5 918.4 918.2 918.0 917.8917.5

L10 917.8 917.8 917.8 917.7 917. 917.6917 .5917 .5917 .4917 .3917 .2917 .0 917.0 916.8916 .6916 .5916 .2

C

By simulation the temperature evolution was determined in all discretized volume elements in the sample-support system (map of temperature at different moments, the local heating speed, the 
temperature repartition on different directions at any moment). A part of the obtained results are shown in Table 2 and Figures $7 \div 10$.

Based on the values in this table, Figure 7 shows the isothermal map (temperature distribution) in section $\mathrm{OABC}$ in the sample-support system at time $t=23.3 \mathrm{~min}$.

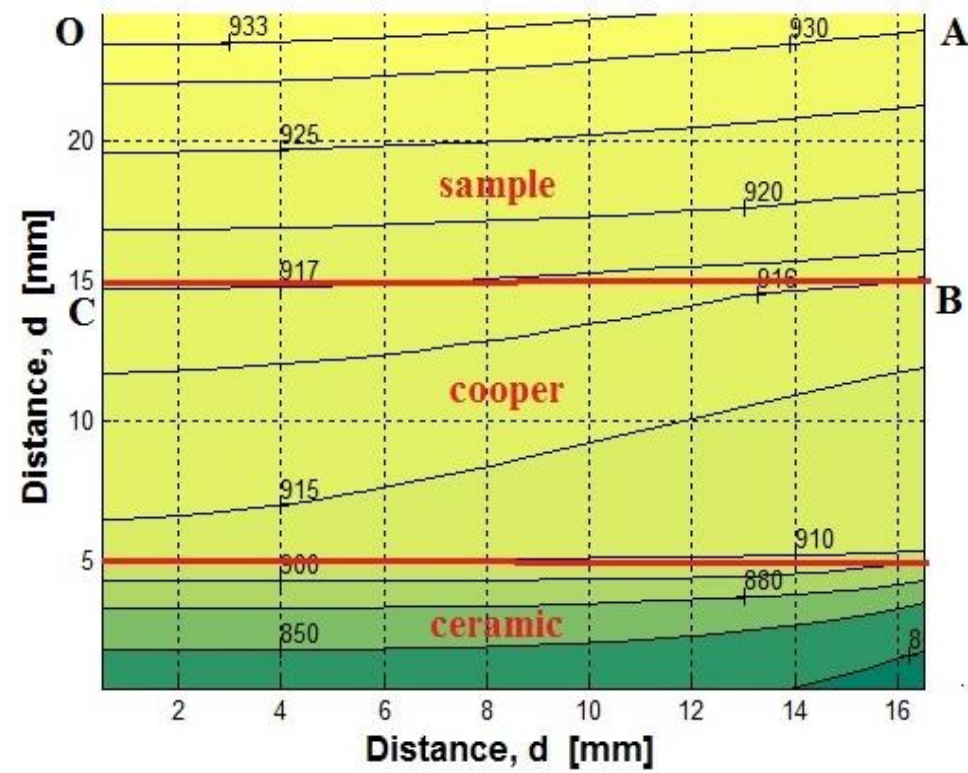

Fig. 7. Temperature map (isothermal lines) by simulation, in ${ }^{\circ} \mathrm{C}$ in the section $\mathrm{OABC}$ - through sample - support assembly at time $\mathrm{t}=23.3 \mathrm{~min}$.

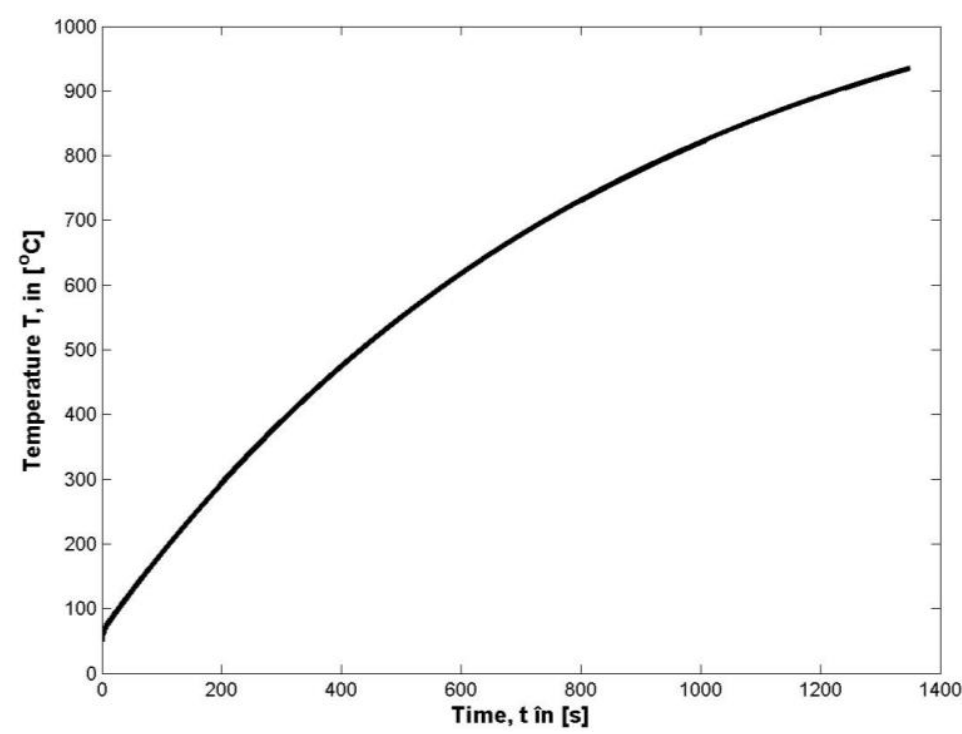

Fig. 8. Heating of the located element in the midpoint of the superficial layer (with $1 \mathrm{~mm}$ thickness) of sample (in 0 point, coordinates $(\mathrm{i}, \mathrm{j}, \mathrm{k})=(1,1,1)$ )

In Figure 8 the curve obtained by simulation regarding the volume element heating of coordinates $(\mathrm{i}, \mathrm{j}, \mathrm{k})=(1,1,1)$ is shown. This point is placed in point $\mathrm{O}$ (Figure 6$)$ and it practically corresponds to the axis of the concentrated radiant spot, incident on the sample surface. Figure 9 shows the distributions of temperature along the $\mathrm{OA}$ line in the superficial layer (with a thickness of $1 \mathrm{~mm}$ ) at time $t=23.3$ min. The temperature along these lines (that corresponds to the longitudinal axis of the sample superior surface) is relatively uniform. The difference between the temperatures of the 0 point (the centre of the surface) and point A (the margin of the surface) is only $14.4^{\circ} \mathrm{C}$ (Table 2). Figure 10 shows the distribution of temperature along the vertical axis of the part-support ensemble (line OC - Figure 
6 ) at moment $t=23.3 \mathrm{~min}$. This figure emphasizes a relatively strong heating of the copper and ceramic plates.

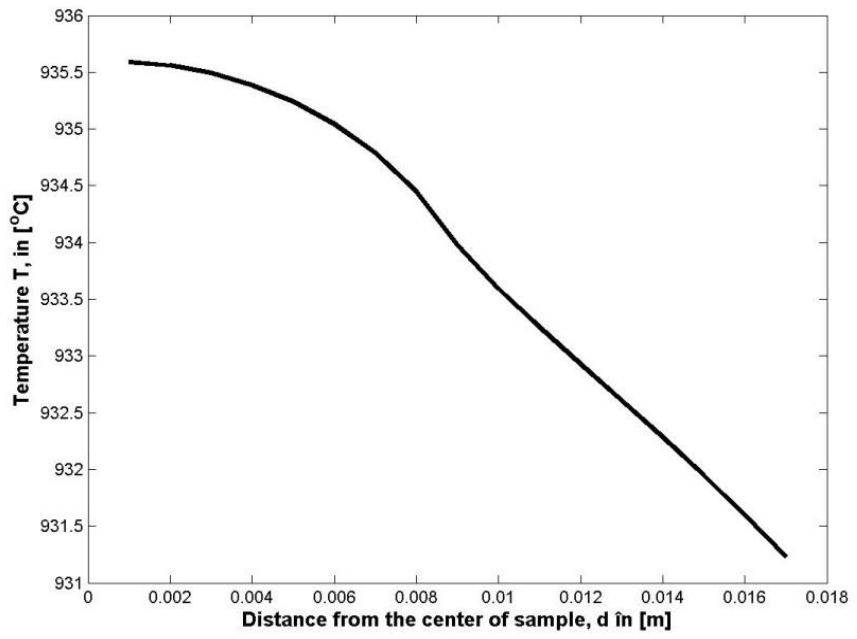

Fig. 9. Temperature in the superficial layer (with $1 \mathrm{~mm}$ thickness) of sample (on OA line) at time $t=23.3 \mathrm{~min}$.

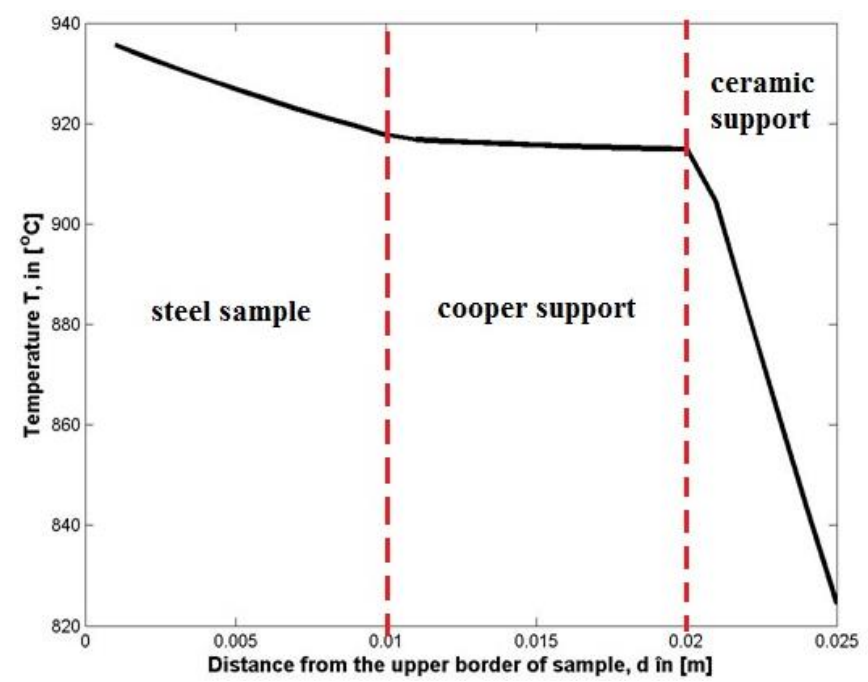

Fig. 10.Temperature on the vertical axis of the part - support assembly (on line OC) at time $t=23.3 \mathrm{~min}$

\section{Conclusions}

The values in Table 2 and Figures $7 \div 10$ show that the steel part is heated in the entire volume a temperature between $936{ }^{\circ} \mathrm{C}$ and $916{ }^{\circ} \mathrm{C}$ (above $900{ }^{\circ} \mathrm{C}$ ). This temperature corresponds to thermic hardening or annealing treatments. The temperature difference in the part section is small enough to obtain structures and uniform properties in the parts volume. The temperature inside the part can be later homogenized even more through short maintaining intervals applied after heating. The working parameters applied in this simulation (valve opening, heating time, etc.) are recommended for the volume hardening of some steel parts with dimensions close to the samples in Figures 5-6. For lowered treatment temperatures (for example $780-840^{\circ} \mathrm{C}$ ) the heating time must be reduced to below 23 min. The heating parameters applied in this experiment are not recommended for surface treatments (for example superficial hardening). For these processes (superficial hardening) a bigger opening of the valves is probably necessary (stronger flux) and much less heating time. That is why there is a continuous need for studies with the help of the simulation to practically set the working conditions of the solar furnaces particularized for other types of thermic treatment (superficial hardening, thin layer covering, etc.) and for parts with different geometry and dimensions. Before launching a production of this product, there is a need for each type of processing (thermic treatment 
type and part tipodimension) for a validation through experiments of the soft's results obtained by simulation.

\section{References}

1. Rodríguez J., Cañadas I., Zarza E. (2014): PSA vertical axis solar furnace SF5. Energy Procedia, ISSN: 1876-6102, vol. 49, p. 1511-1522, DOI: 10.1016/j.egypro.2014.03.160

2. Llorente J., Vázquez A.J. (2009): Solar hardening of steels with a new small scale solar concentrator. Materials Chemistry and Physics, ISSN: 0254-0584, vol. 118, is. 1, p. 86-92, DOI: 10.1016/j.matchemphys.2009.07.008

3. Karalis D.G., Pantelis D.I., Papazoglou V.J. (2005): On the investigation of 7075 aluminum alloy, welding using concentrated solar energy. Solar Energy Materials \& Solar Cells, ISSN: 0927-0248, vol. 8, is. 2, p. 145-163, DOI: 10.1016/j.solmat.2004.07.007

4. Sarver T., Al-Qaraghuli A., Kazmerski L.L. (2013): A comprehensive review of the impact of dust on the use of solar energy: History, investigations, results, literature, and mitigation approaches. Renewable and Sustainable Energy Reviews, ISSN: 1364-0321, vol. 22, p. 698-733, DOI: 10.1016/j.rser.2012.12.065

5. Pitts J.R., Stanley J.T., Fields C.L. (1990): Solar Induced Surface Transformation of Materials. In Proceedings of the Fourth International Symposium Solar Thermal Technology: Research Development and Applications, ISBN 978-1560320951, p. 459-470

6. Vázquez A.J., Rodriguez G.P., de Damborenea J. (1991): Surface Treatment of Steels by Solar Energy. Solar Energy Materials, ISSN: 0927-0248, vol. 24, iss. 1-4, p. 751-759, DOI: 10.1016/0165-1633(91)90108-W

7. Rodriguez G.P., Lopez V., de Damborenea J., Vázquez A.J. (1995): Surface transformation hardening on steels treated with solar energy in central tower and heliostats field. Solar Energy Materials \& Solar Cells, ISSN: 0927-0248, vol. is. 1, p. 1-12, DOI: 10.1016/0927-0248(94)00169-S

8. Soporan V., Constantinescu V. (1995): Modelarea la nivel macrostructural a solidificării aliajelor (Macrosolidification Modelling of alloys solidification). Editura Dacia, ISBN 973-35-0526-9, Cluj-Napoca, Romania (in Romanian)

9. Soporan V., Constantinescu V., Crișan M. (1995): Solidificarea aliajelor, preliminarii teoretice (Solidification of Alloys, Theoretical Preliminaries). Editura Dacia, ISBN 973-97041-1-5, Cluj-Napoca, Romania (in Romanian)

10. Soporan V., et al. (2010): Modelarea matematică a proceselor care au loc la turnarea pieselor metalice (Mathematical Modelling of the Process from Metalic Castining). Editura Casa Cărții de Știință, ISBN 978-973133-059-4, Cluj-Napoca, Romania (in Romanian)

11. Soporan V., Vamoş C., Pavai C. (2003): Modelarea numerică a solidificării (Numerical Modelling of Solidification). Editura Dacia, ISBN973-35-1645-7, Cluj-Napoca, Romania (in Romanian)

12. Monescu V. (2010): Realizarea unui program 3D pentru simularea solidificării pieselor turnate (3D Software for casing solidification simulation). PhD thesis, Transilvania University of Brasov, Romania (in Romanian)

13. Ionescu D. (2014): Simularea solidificării pieselor turnate din aliaje cu solidificare în interval de temperatură (Computer Simulation of the Solidification of Castings from Alloys Solidifying within a Temperature Interval). $\mathrm{PhD}$ thesis, Transilvania University of Brașov, Romania (in Romanian)

14. Ionescu I.C. (2015): Cercetări privind simularea solidificării pieselor turnate cu simetrie de rotaţie (Researches Regarding the Solidification Simulation of Casting with Rotational Simetry). PhD thesis, Transilvania University of Brașov, Romania (in Romanian) 